rev.relac.int.estrateg.segur.8(2):15-36,2013

\title{
LA CRISIS EUROPEA ACTUAL ${ }^{1}$
}

\author{
Pedro Nel Páez Pérez ${ }^{2}$ \\ Jorge Isaza Quebrada ${ }^{3}$ \\ Luz Amanda Zamora ${ }^{4}$
}

\section{RESUMEN}

La Unión Europea está viviendo una profunda crisis económica que se ha materializado en las tasas negativas de crecimiento y en el alto desempleo, factores que han dado lugar a un ajuste severo y a medidas de austeridad, que reducen la calidad de vida de millones de personas en el continente. El principal objetivo de este informe de investigación, es aportar una explicación a la crisis europea y a los efectos que tiene sobre el bienestar de sus habitantes. Igualmente señala la relación entre la crisis financiera y el sector real, destacando algunos de los mecanismos de transmisión que terminan por afectar las tasas de crecimiento económico. La última parte recoge los fragmentos más importantes de las diferentes

1. Informe final de la investigación VICEIN-R-014, Centro de Investigaciones FARIES-UMNG.

2. Ph.D en Economía. Profesor Escuela Superior de Administración Pública. Comentarios a: pedronelpaez@gmail.com

3. Decano Facultad de Relaciones Internacionales, Estrategia y Seguridad. Universidad Militar Nueva Granada.

Comentarios a: Jorge.isaza@unimilitar.edu.co

4. Coinvestigadora. Maestría en Relaciones y Negocios Internacionales, Universidad Militar Nueva Granada.

Comentarios a: luzamanda511@hotmail.com 
teorías respecto a la Unión Europea, así como los elementos fundamentales que asistieron a su creación y también pone de relieve puntos críticos que afectan a la Unión Europea, debido a las situaciones derivadas de la crisis.

Palabras clave: crisis europea, bienestar, endeudamiento, titularización, apalancamiento, teorías de las relaciones internacionales.

\title{
THE CURRENT EUROPEAN CRISIS
}

\begin{abstract}
The European Union is undergoing a profound economic crisis that has resulted in negative growth rates and high unemployment, which have led to a severe adjustment and austerity measures that reduce the quality of life of millions of people in the continent. The main objective of this research report is to provide an explanation of the European crisis and its effects on wellbeing. It also outlines the relation between the financial crisis and the real sector, highlighting some of the transmission mechanisms that eventually affect economic growth rates. The last part contains the most important fragments of the different theories of the European Union, as well as the fundamental elements that attended its creation and also highlights critical points that affect the Union, due to circumstances arising from the crisis.
\end{abstract}

Keywords: European Crisis, wellbeing, debt, securitization, leverage, theories of international relations.

\section{CRISE EUROPEIA ATUAL}

\section{RESUMO}

A União Europeia está passando por uma crise econômica profunda, que resultou em taxas de crescimento negativas e elevado desemprego, em consequência, levou a um severo ajuste e medidas de austeridade, que reduzem a qualidade de vida de milhões de pessoas no continente. O principal objetivo deste relatório de pesquisa é fornecer uma explicação da crise europeia, seus efeitos sobre o bem-estar social. Também mostra a relação entre a crise financeira e o setor real, destacando alguns dos mecanismos de transmissão que eventualmente afetam as taxas de crescimento econômico. A última parte contém os fragmentos mais importantes das diferentes teorias da União Europeia, bem como os elementos fundamentais que participaram da sua criação e também destaca os pontos críticos que atravessa a União devido às circunstâncias decorrentes da crise.

Palavras-chave: crise europeia, bem-estar, dívida, securitização, alavancagem, das relações internacionais. 


\section{INTRODUCCIÓN}

Quizás la palabra que mejor refleja la situación europea actual sea incertidumbre. Ante la magnitud y duración de la crisis económica y social, no se vislumbra una salida pronta a los problemas de producción y desempleo a pesar de las rigurosas medidas de austeridad, contestadas con movilizaciones multitudinarias a lo largo y ancho de Europa.

Este documento es el primer informe de la investigación "La Crisis de la Deuda en la Zona Euro: los Mecanismos de Transmisión y Efectos en el Tercer Mundo", auspiciado por el Centro de Investigaciones de la Facultad de Relaciones Internacionales, Estrategia y Seguridad de la Universidad Militar Nueva Granada.

El objetivo fundamental es analizar la crisis europea actual. En la sección 1 se presenta un breve recuento de las crisis que han afectado a diversas regiones del mundo, diferentes a Europa. En la sección 2 se propone una definición de las crisis económica y financiera. La sección 3 analiza la naturaleza de la crisis europea. La sección 4 hace un recorrido por la integración europea, desde la perspectiva de las diferentes corrientes de las relaciones internacionales y los problemas que enfrenta a raíz de la crisis.

\section{LA CRISIS EUROPEA}

Europa atraviesa por una crisis económica y social sin precedentes, por lo menos desde la Gran Depresión. En Portugal, Italia, Grecia y España 'PIGS', por sus siglas en inglés, la producción se ha desplomado desde el año 2008, y en el año 2012 alcanzó unos registros inusuales. Grecia observó una caída del 6\%, Portugal 3\% e Italia 2.3\%. España apenas creció 0.2\% (Gráfico 1). A noviembre del mismo año, el desempleo afectó al $26 \%$ de la fuerza laboral en Grecia y España mientras que en los otros dos países superó los dos dígitos: $11.1 \%$ en Italia y 16,3\% para Portugal (Tabla 1).

Tabla 1. Tasa de desempleo, PIGS

\begin{tabular}{|l|r|}
\hline \multicolumn{2}{|c|}{ TD PIGS } \\
\hline Portugal & 16,30 \\
Italia & 11,1 \\
Grecia & 26,80 \\
España & 26,6 \\
\hline
\end{tabular}

Fuente: Eurostat 
Por su severidad, la Unión Europea -UE- ha tenido que adoptar estrictas medidas de austeridad, recortando los presupuestos públicos y elevando los impuestos (principalmente al valor agregado). El rigor del ajuste sugiere efectos negativos desde el punto de vista social, pues la disminución del gasto público significa el desmonte de programas sociales, mientras que los impuestos indirectos castigan a la distribución de la renta, pero contraen del mismo modo el consumo en los hogares y la producción.

Un elemento significativo de los programas de ajuste es la reforma a la legislación laboral, que flexibiliza el mercado de trabajo, con el invariable descenso y congelamiento de los salarios. Igual suerte corren las primas laborales, las indemnizaciones, el periodo de vacaciones y las pensiones, sometidas éstas al aumento de la edad y el recorte en las mesadas. Mientras los trabajadores ven obstaculizada las negociaciones colectivas, a las empresas se les posibilitan los despidos con un recorte desmedido en la duración y cantidad de los beneficios al desempleo, por lo que cobran fuerza el trabajo temporal y a tiempo parcial (Laven y Santi, 2012:1). La seguridad social europea ha sido presa de la crisis con la disminución de las prestaciones sociales y de la inversión pública, pero sin lugar a dudas, genera preocupación por la forma en que terminará afectando al resto del planeta, especialmente a los países del Tercer Mundo.

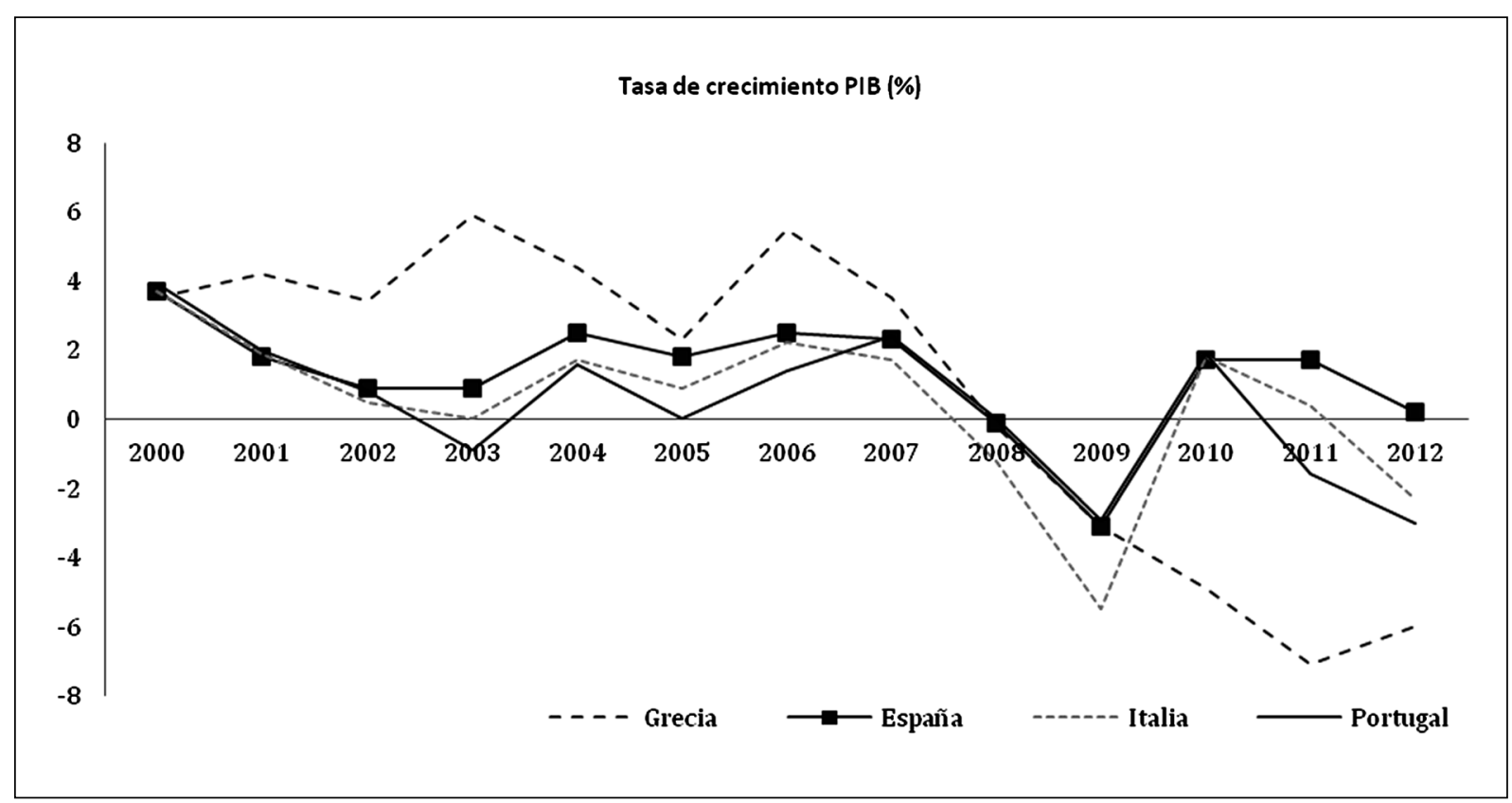

Gráfico 1. Tasa de crecimiento del producto PIGS, 2000-2012.

Fuente: Elaboración propia con base en Eurostat 
Si la situación es compleja en los PIGS, también lo es para el conjunto de la UE. En el año 2012 la tasa global de crecimiento fue negativa (-0.3\%), con un desempleo de $11.8 \%$ de la Población Económicamente Activa -PEA- (Eurostat, 2013). En mayor o menor medida, todos los países de la UE han sido golpeados por la crisis y han tenido que adoptar medidas de ajuste, con excepción de Alemania.

Una manifestación de la crisis es la pérdida de bienestar social y el deterioro de las condiciones de vida. Las secuelas más previsibles han sido el aumento de la pobreza, la desigualdad, la exclusión social y la caída de la renta per cápita. En el primer caso, se estimaba que para el año 2010 el 23\% de población europea (unos 115 millones de personas), estaba en riesgo de caer en pobreza ${ }^{5}$ o padecer la exclusión social. Pero la cifra fue mayor para las personas menores de 18 años con un 27\% (ibíd.), lo que demuestra que están en una situación de privación material severa o viviendo en un hogar con baja intensidad laboral ${ }^{6}$. Según las cifras disponibles en Eurostat, el $8 \%$ de la población estaba en una condición de privación material severa ${ }^{7}$, donde la calidad de vida y el bienestar, se limitan por la carencia de recursos.

La crisis además de ser una contracción violenta de las tasas de crecimiento, también es una crisis social (Bonesmo-Fredriksen, 2012:4). La reacción social han tenido como consecuencia manifestaciones multitudinarias a lo largo y ancho de Europa, como expresiones del malestar y el inconformismo ante las drásticas medidas de austeridad, pero no han sido echadas atrás. Bonesmo (ibíd.: 6) encuentra un incremento de la desigualdad en la UE por el ingreso de países muy pobres como Bulgaria, Eslovaquia y Estonia, pero del mismo modo por el efecto negativo de la globalización. Por su parte, el PIB per cápita de Italia, Grecia y España ha disminuido con respecto a la media europea, lo cual es uno de los efectos más tangibles de la contracción productiva, el desempleo y la austeridad, aspectos que claramente están en contravía a la integración económica y política.

\section{La naturaleza de una crisis}

En esta sección se plantea el análisis de la crisis europea en los aspectos financiero y económico. Interesan los impactos sobre el crecimiento de la producción agregada y los mecanismos de transmisión, su duración y las causas.

5. Aquellas personas que viven en un hogar con un ingreso disponible equivalente -que está por debajo del umbral de riesgo de pobreza-, el que se ha fijado en el $60 \%$ del ingreso disponible nacional promedio, después de transferencias sociales.

6. Personas entre 0-59 años que viven en hogares donde en promedio los adultos (entre 18 y 59 años) trabajaron menos del $20 \%$ de su trabajo potencial total en el año inmediatamente anterior. Se excluyen los estudiantes.

7. Personas que tienen unas condiciones de vida en las que la carencia de recursos hace que enfrenten carencias por lo menos en cuatro de nueve de las siguientes características: No pueden o no tienen 1) Para pagar la renta o hipoteca de la vivienda o los recibos de los servicios públicos, 2) Un hogar con calefacción adecuada, 3) Los ingresos para gastos inesperados, 4) Para comer carne, pescado o una proteína equivalente cada dos días, 5) Un fin de semana fuera del hogar, 6) Tener un automóvil, 7) Una lavadora, 8) Un televisor a color, 9) Un teléfono (incluyendo un teléfono celular). (Ver Eurostat, 2012). 


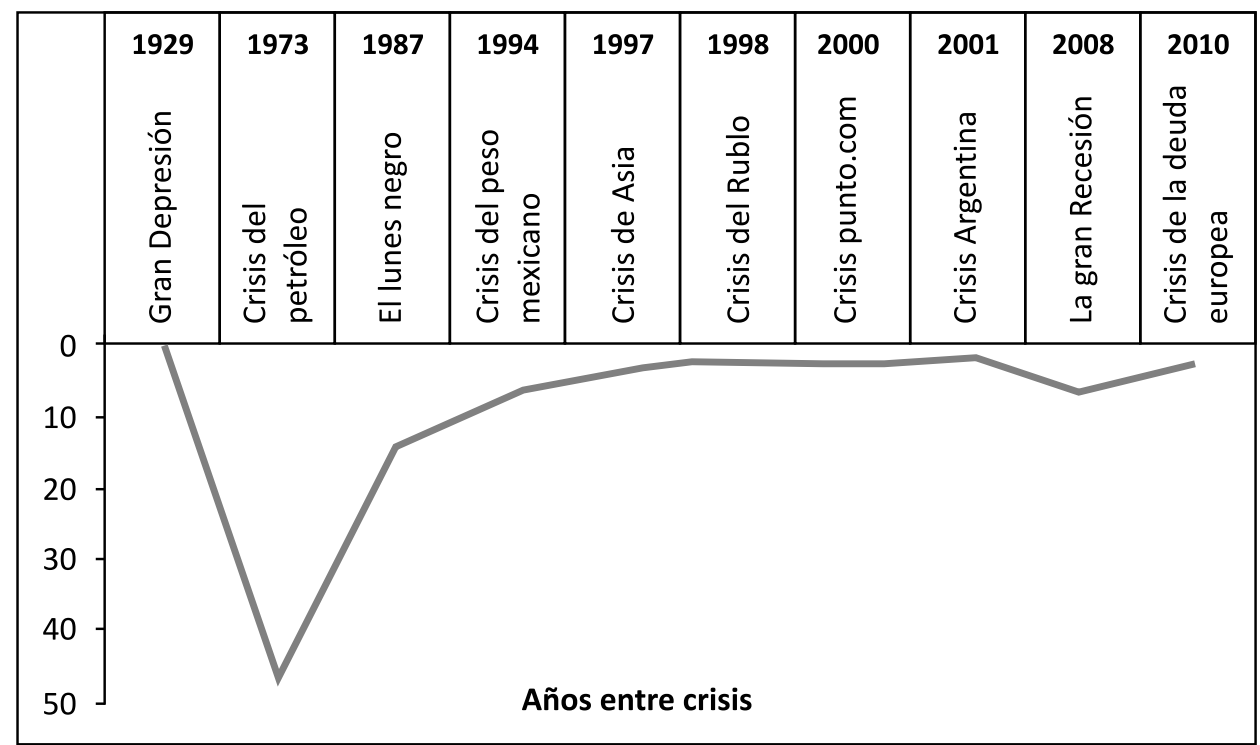

Gráfico 2. Relación entre crisis y tiempo, elaboración propia.

Fuente: Elaboración propia.

Las preocupaciones sobre la situación europea pueden parecer absurdas porque se viven en países desarrollados, pero son frecuentes en otras regiones diferentes a Europa, habida cuenta que el mundo ha experimentado, según las estimaciones más conservadoras, por lo menos diez crisis significativas entre los años 1929 y 2012. Esto equivale a decir que cada 8,3 años se padece una crisis, aunque este promedio simple no muestre las discrepancias temporales como tampoco las particularidades asociadas con cada uno de estos episodios. Sin lugar a dudas, ahora las crisis son más recurrentes y se han dado todas ellas en un período de tiempo inferior a un siglo, aproximadamente 83 años. Es así como entre la Gran Depresión (1929) y la primera crisis del petróleo (1973), transcurren 44 años. De ahí en adelante, los periodos son cada vez más breves. (Gráfico 2). Muestra de ello es que entre la crisis del petróleo (1973) y el Lunes Negro (1987), transcurren 14 años; pero entre éste último y la crisis del peso mexicano pasan apenas cuatro años. Y de ahí a la Crisis Asiática, escasamente dos años.

En segundo lugar, siempre se ha observado una relación negativa entre crisis y producción. Una crisis económica se entiende como la contracción o una tendencia declinante y persistente en las tasas de crecimiento de la renta, con un marcado aumento del desempleo y elevados costos sociales. El punto hay que recalcarlo por la presunta relación positiva que los economistas neoclásicos encuentran entre el crecimiento y el bienestar. Se supone que lo contrario también es cierto, que una crisis se traduce en pérdida de bienestar. La correspondencia negativa entre crisis y crecimiento muestra una realidad insoslayable: Durante el punto más crítico de la Gran Depresión (1933), el producto industrial de Estados Unidos se contrajo en 
un 47\% (Levine, 2009:6) y el PIB real en un 30\%, mientras que la tasa de desempleo alcanzó a una cuarta parte de la fuerza laboral, (Romer, 2003:1). Uno de cada cuatro trabajadores estaba empobrecido y además desocupado.

En los años 70 la crisis del petróleo significó un acelerado proceso de endeudamiento para el mundo no desarrollado. Una de sus consecuencias fue la caída de la producción real en un 8.9\% entre 1981-1984 (Griffith-Jones y Sunkel, 1987: 7 y ss.). El 19 de octubre de 1987 o Lunes Negro, se dio la venta masiva de acciones en la Bolsa de Nueva York y la reducción del índice S\&P 500 en un 22\% (Carlson, 2006:18), perdiéndosen alrededor de 300.000 mil millones de dólares, dineros que los contribuyentes norteamericanos tenían en cuentas de ahorro y préstamos de dudosa calidad. Este colapso bursátil no estuvo exento de escándalos protagonizados por las instituciones financieras y las repercusiones de esta recesión se sienten incluso hoy en día, tal como lo resalta GARP, (2004). La devaluación masiva del peso mexicano en 1994 tuvo efectos negativos sobre la actividad económica de toda América Latina, específicamente sobre la inflación, las tasas de interés, el servicio de la deuda y el desplome de los indicadores bancarios. Con justa razón se ha denominado la Crisis del Peso Mexicano (Arnaudo, Querol y Pérez, 2003:4). Otro episodio de devaluación se dio en Tailandia en 1997, desatando la crisis de Asia, que le costó a ese país el 35\% del PIB entre los años 1997 y 2003; pero afectó simultáneamente las economías de Malasia, Indonesia, Filipinas, Taiwán, Hong Kong y Corea del Sur (Noy, 2005:6). Por su parte, el colapso del sistema bancario ruso en 1998 o Crisis del Rublo, obligó a la suspensión parcial de los pagos internacionales. Junto con la devaluación, Rusia terminó el año 1998 con una disminución de la producción real de 4,9\% (Chiodo y Owyang, 2002:10).

Un año después de la crisis del rublo en el año 1999, se vivió la crisis de las empresas puntocom, que llevó a la quiebra a las compañías de esa nueva economía y a empresas de capital de riesgo. Además, representó la reducción de los planes de pensiones con prestación definida ya que "...entre 2000 y 2004 hubo una tendencia de continuo deterioro de los fondos de pensiones de Canadá, Japón, Reino Unido y los Estados Unidos" (Tondo, 2009:45).

Posteriormente sobreviene la crisis argentina entre los años 2001 y 2002. Entonces, la incapacidad de mantener la paridad del peso argentino frente al dólar favoreció una fuga masiva de capitales, lo que llevó al gobierno a imponer restricciones sobre los retiros bancarios, situación conocida como el "corralito". La producción real se contrajo en un 28\% entre los años 1998 y 2002 (Saxton, 2003:1). A su vez, en el año 2008, Estados Unidos soportó la crisis asociada con la especulación financiera y crediticia, que terminó con la burbuja inmobiliaria y las hipotecas basura (sub-prime). Esta crisis, catalogada como una de las peores en la historia de ese país, representó una caída en la producción cercana al 5\% del PIB entre los años 2007-2009, así como la pérdida de casi $9^{\prime} 000.000$ de puestos de trabajo y cerca de 20 billones (millones de millones) de riqueza de los hogares de Estados Unidos, de acuerdo con el Departamento del Tesoro (US Departament of Treasury, 2012:3). 
Por último, no hay certeza sobre cuando se pueda superar la crisis europea actual. Ha sido costosa en términos de producción y empleo, y la incertidumbre no permite optimismo sobre las consecuencias sobre países como Colombia, que apenas se han visto afectados marginalmente.

Con ese panorama debe recalcarse, que curiosamente, las crisis han sido más frecuentes durante la globalización que bajo el predominio de la economía keynesiana y la intervención, así como durante la regulación estatal.

A pesar de la relevancia que en estos momentos adquiere el significado de la crisis, sobre todo por sus implicaciones económicas y sociales, surge una dificultad asociada con su definición. La literatura no explica muy bien cuál es su naturaleza. Aquí se intentará una definición que, como toda definición es provisional pero queda expuesta, como es natural, a limitaciones, críticas y a los comentarios pertinentes. Una crisis económica es un descenso en la producción de bienes y servicios, medido por la tasa de crecimiento del PIB real, que se origina en uno o varios países en un periodo relativamente largo de tiempo, en todo caso superior a un año, y que tiene efectos sociales adversos que se propagan a través del desempleo, la desprotección social y el descenso de los salarios y las medidas de austeridad con que se trata de detener la crisis. Puede extenderse a más de un país a la vez; sus causas son reales o financieras o una combinación de éstas.

Empero hay que expresar algunos comentarios que se originan de esta definición. Toda crisis se traduce en pérdida de producción, empleo y bienestar; el resultado de muchos efectos que sumados, adquieren las características de un desastre. Pero por otra parte, hay que discernir sobre las explicaciones de las crisis en la medida en que hay más de un enfoque para explicarlas. Por último, no toda contracción del PIB representa una crisis, por lo que pueden determinarse tres escenarios: la desaceleración, la recesión y la crisis. La desaceleración es una reducción transitoria de la tasa de crecimiento de la producción; esta tasa es menor (no necesariamente negativa) comparada con un periodo anterior. Si por ejemplo, una economía crece en un periodo $5 \%$ y $3 \%$ en otro, la economía está experimentando una desaceleración.

Por su parte, habrá una recesión cuando la tasa de crecimiento se contrae por más de dos trimestres consecutivos. La crisis inevitablemente debe pasar por las etapas de desaceleración y recesión, pero es claro que en esta última, la contracción tiene un período de duración más largo y en consecuencia, la crisis económica es aquella disminución significativa de la tasa de crecimiento del PIB en un período de tiempo mayor, que eventualmente puede propagarse por más de un país.

Otra regularidad innegable es que una crisis está precedida por periodos de crecimiento extraordinario. La Gran Depresión fue antecedida por una fase de crecimiento dinámico durante los años 20's (Rothbard, 2000:91). De acuerdo con Thomassen (1990:103), la prosperidad de los años 60's desaparece con la crisis del petróleo en los años 70's; y los felices años 90's (Stiglitz, 2003:14) acabaron también en una crisis. El precedente del conflicto de crecimiento actual en Estados Unidos y Europa, estuvo antecedido por la burbuja inmobiliaria. 


\section{EXPLICACIONES Y CAUSAS}

\section{- Teoría del Ciclo Real}

La actual crisis europea se ha explicado desde varias perspectivas, entre ellas una que aparece como muy natural o lógica y que viene en dos vertientes: La teoría tradicional del ciclo y la Teoría del Ciclo Real TCR) o Real Business Cycle (RBC). Desde la primera, la producción de un país se caracteriza por una tendencia suavizada de las tasas de crecimiento, que varían muy poco en el tiempo. El ciclo es entonces una desviación del crecimiento o bien por encima, cuando la tasa de crecimiento es mayor al promedio, o por debajo de esa tendencia, cuando la tasa es negativa. Para la TCR (Long y Plosser, 1883:39); Hodrick y Prescott, 1980:1; (Kidland y Prescott, 1982:1345), se asume que las variables económicas agregadas en una economía capitalista experimentan fluctuaciones frecuentes alrededor de sus trayectorias de crecimiento de largo plazo (Lucas, 1981:19). La producción evoluciona en el tiempo, como es correcto suponer, pero tiene un componente aleatorio o impredecible (random walk) y las oscilaciones de la producción (Mankiw, 1989:79) se deben a las variaciones aleatorias en la tasa de crecimiento del sector real; así la crisis se explica desde la pérdida de productividad.

Los cambios en la producción se asocian con choques o perturbaciones tecnológicas, que tienen consecuencias negativas sobre la productividad y se propagan a través de la inversión. En esta perspectiva no se considera que las desviaciones sean causadas por alguna tendencia. Se cree que la producción pasada tiene un efecto sobre la producción presente, junto con el efecto de los componentes aleatorios. Los teóricos de la TCR estiman los choques de productividad con el residuo de Solow, que es una medida de la variación de la productividad total de los factores y descompone el crecimiento de la producción agregad: una debida al crecimiento de los factores productivos (capital y trabajo) y otra debida al progreso tecnológico.

\section{- Las crisis financieras}

Si bien la TCR analiza los factores reales que afectan la productividad de los factores y su efecto sobre las tasas de crecimiento del PIB, ella excluye el papel que juegan los componentes financieros que anteceden a las crisis económicas. Esta limitación es recogida por otros enfoques que subrayan la importancia que adquieren las variables financieras sobre la contracción de la producción. Con su análisis se pueden determinar los mecanismos de transmisión al sector real. Bajo los supuestos más ortodoxos, el sector financiero intermedia dinero hacia el sector productivo y se presume asimismo que la asignación alcanzada es eficiente. Con perfecta movilidad de capitales, se reducen los costos de intermediación y se multiplican los recursos disponibles por una mayor liquidez. Si así ocurriese, los países del Tercer Mundo igualmente serían beneficiarios de la eficiencia en el flujo de capitales. Pero los argumentos anteriores dejan de tener validez en una crisis financiera por la escasez y el encarecimiento de los recursos, secuelas que se van trasmitiendo gradualmente al sector real y terminan por colapsar la economía, incluido el mismo sector financiero. 
Las crisis financieras se han clasificado como: fiscales bancarias y burbujas especulativas (Radelet y Sachs, 1998:4 y ss.). De acuerdo con Sachs (1995:1 y ss.) sus causas más habituales son las perturbaciones exógenas, tales como el deterioro de los términos de intercambio, pues reduce la capacidad de pago de economías muy endeudadas y lleva hacía una crisis bancaria, que puede llegar a ser muy difícil para países con una oferta exportadora poco diversificada. Otra causa es la volatilidad de los tipos de interés del resto del mundo sobre las economías domésticas, porque amplifica la carga de endeudamiento que asume el país deudor que soporta al mismo tiempo la escasez de divisas. La salida de capitales afecta al capital bancario, al crédito y a las obligaciones contraídas sobre la deuda (interna y externa). Estos factores encarecen los recursos porque decrece la disponibilidad para prestarle a un país cuando prácticamente está arruinado; por lo que se reducen las fuentes de financiamiento y se resquebraja la solvencia del sistema bancario. Otra perturbación se ha asociado con la política económica y la cuenta de capitales. Una apreciación colapsa la balanza de pagos, Puesto que en términos relativos, hace menos competitivas las exportaciones con efectos potenciales sobre un mayor endeudamiento, que puede llegar a ser excesivo e inducir igualmente a una crisis bancaria.

Entre las causas menos ortodoxas se encuentran la desregulación de las transacciones financieras a gran escala, la falta de transparencia y de control aplicables al mercado financiero, la creación y venta de títulos valores, y los préstamos a personas sin capacidad de pagar los créditos. La combinación de crédito abundante con tipos de interés bajo, estimula la demanda de activos financieros que aumentan sus precios. Cuando bajan, tienen un efecto grande sobre el sector financiero y estimulan el estallido de una burbuja especulativa, ya que los precios han crecido hasta niveles insostenibles. También hay que destacar el papel que juega el fenómeno de la titularización, pues allí está una de las causas de la crisis financiera porque reduce los incentivos por la prudencia y lleva a demandar activos de alto riesgo. Por último, las agencias calificadoras clasifican positivamente activos que posteriormente se degradan a la categoría de títulos basura.

Una crisis de deuda sobreviene cuando un país no puede pagar las obligaciones crediticias sin la ayuda de terceras partes. Las instituciones financieras colapsan y aumentan las exigencias de rentabilidad esperada para los bonos de deuda soberana. La forma más frecuente de que un país se endeude es a partir de la emisión de bonos que se colocan en el mercado de capitales doméstico o internacional. Los inversionistas adquieren deuda de un país cuando compran sus bonos para obtener beneficios o especular con ellos. Cuando la dinámica del gasto sigue la misma dirección del endeudamiento y el aumento progresivo del gasto se financia con más deuda sin generar una contrapartida en austeridad, crecimiento económico o recaudo tributario, en el mediano-largo plazo la acumulación de deuda se vuelve insostenible porque desemboca en el incumplimiento de los pagos con los acreedores (default) y posiblemente ocasiona una crisis bancaria (Liu y Morley, 2012:7).

La insostenibilidad del endeudamiento demanda más recursos financieros para pagar las obligaciones contraídas en un mercado internacional, que difícilmente le presta a un país que está al 
borde de la quiebra y los inversionistas se deshacen de los bonos porque han perdido su valor. El país insolvente enfrenta una situación de crisis ya que está virtualmente quebrado; no consigue créditos nuevos y encontrar un salvamento en esas circunstancias implica la adopción de medidas de austeridad extremas que afectan los ingresos de los ciudadanos y resulta en una crisis económica generalizada.

Para entender una crisis bancaria debe recordarse que el papel de los bancos es intermediar recursos entre los ahorradores y aquellos que demandan el dinero. Ellos captan capitales de corto plazo para prestarlos de nuevo o comprar activos que maduran en un lapso de tiempo mayor. Si pierden dinero con estas transacciones, asoman dudas sobre la solvencia y solidez del sistema, y en consecuencia se hace necesaria la intervención de un prestamista de última instancia, frecuentemente el banco central, que suministra la liquidez para sostenerlo. En caso contrario, los pasivos de los bancos superan el valor de sus activos y los ahorradores retiran los fondos masivamente. Si el banco central proporciona la liquidez necesaria, el procedimiento concluye con el rescate, la nacionalización o el cierre de los bancos para evitar los retiros. No obstante, cuando hay dudas justificados sobre la liquidez, los inversionistas retiran el dinero masivamente y si como lo suponen Nakagawa y Uchida (2007:3), sobreviene un comportamiento de manada, los retiros masivos quiebran el sistema, presentándose pérdidas muy grandes en el sector real.

Una burbuja financiera especulativa ocurre cuando los inversionistas adquieren un activo a un precio superior a su valor de mercado, con la expectativa de obtener beneficios extraordinarios en un futuro cercano. La fase expansiva de una economía está acompañada por el crecimiento exponencial del crédito, las transacciones financieras e innovaciones sectoriales, elementos que generan volúmenes extraordinarios de datos en tiempo real. Esta dinámica desborda la regulación existente y le resta transparencia a las transacciones, pero estimula la especulación y la concentración sectorial (Reza y Lim 2011:24), que termina en una tergiversación del proceso de asignación de recursos por los fallos regulatorios asociados. Estos elementos crean las condiciones para que aumente la probabilidad de una crisis financiera, que en algún momento se traslada al sector real (Kapoor, 2010:37) en medio de severas restricciones crediticias. El incremento de los tipos de interés paraliza el flujo de liquidez hacia el sector productivo.

En el mercado de capitales, cuando sube el precio de un activo, no necesariamente disminuye la demanda; por el contrario y contradiciendo la lógica impuesta por la ley de la demanda, es bastante probable que aumente. Los inversionistas apuestan a que el precio de un activo siga una espiral alcista continua de la demanda y los precios, que en algún momento tienen que explotar (Kindleberger, 1978:3). La especulación, afincada en la expectativa de precios crecientes que induce el incremento de la demanda, genera en la población el deseo de ganar más dinero que no se genera en una actividad real, sino en la demanda exagerada de activos que sobrevaluan su precio y crea inestabilidades en el sector financiero, lo que puede terminar en un riesgo sistémico. En relación con la producción, la actividad financiera genera información decisiva para la determinación de los tipos de interés, la inversión, la producción y el nivel de 
precios, como también para aquellas estrategias de estabilización asociadas con las políticas macroeconómicas. En esta categoría de crisis financiera se encuentra el Lunes Negro. El derrumbe del mercado accionario adquirió las proporciones de un choque sistémico y comprometió la estabilidad del sistema financiero, como lo apunta Carlson (2007:21), lo mismo que la crisis de Asia y la crisis hipotecaria de los Estados Unidos.

\section{Entonces, ¿Qué es lo que ha pasado en Europa?}

Es necesario echar una mirada a cómo Europa llegó a la situación que está viviendo. El problema se origina con el auge del crédito y la baja de los tipos de interés de corto plazo y largo plazo, política monetaria y deuda respectivamente, los que incitaron un proceso de endeudamiento para la periferia europea. Los intereses y el servicio de la deuda fueron menores al promedio histórico (Lane, 2012:54). En medio de la euforia crediticia se dio una dinámica de endeudamiento creciente, pero hay dos escenarios que es importante analizar. Uno de ellos está en el origen de la crisis y se presenta en Estados Unidos con el aumento de la liquidez por la afluencia de capitales provenientes de China y Japón que se invirtieron en el sector inmobiliario, situación que presionó la baja de los tipos de interés y estimuló la demanda en el sector inmobiliario. Asimismo, los activos subyacentes ven aumentar sus precios por la especulación. El segundo escenario es el europeo y particularmente los países periféricos, ya que la disposición de liquidez favoreció la expansión del crédito en el sector de bienes no transables y la compra de vivienda, sin priorizar la inversión en capital, lo que terminó afectando negativamente la productividad de los PIGS y creando desequilibrios externos significativos. La laxitud fiscal, por otra parte, hace que esta política sea mucho menos contra-cíclica.

Es importante señalar el papel que juega en esto la especulación. El auge de la titularización en el mercado financiero internacional se relaciona con la crisis de las hipotecas en los Estados Unidos, junto con una actitud permisiva hacia el riesgo y las primas relacionadas. También el incremento de la demanda y los precios de las viviendas y los activos asociados con la actividad hipotecaria, serían el resultado más visible de la especulación en el sector inmobiliario. A los anteriores factores es necesario adicionar también el fenómeno del apalancamiento, que coadyuva a dinamizar aún más la demanda por activos inmobiliarios, ante las expectativas de ganancias y la subvaloración del riesgo.

En ese ambiente de 'dinero fácil' y además barato, juega un papel importante la titularización (liquidity transformation), la utilización de activos líquidos para fondear activos no líquidos, que viabiliza la colocación de hipotecas o créditos comerciales en vehículos de propósito especial (Special Purpose Vehicles, SPV), emisión de bonos contra activos sin liquidez. Las hipotecas se han vuelto 'líquidas' y se comercializan a través del sistema bancario a la sombra (Shadow Banking System), que son intermediarios financieros representados por la banca de inversión, los fondos de cobertura (hedge funds) los fondos mutuos (mutual funds) los vehículos de inversión estructurados y corredores hipotecarios (mortgages brokers), que si bien desempeñan un 
papel significativo en el mundo financiero moderno, también lo juegan en la especulación. A través de este sistema a la sombra, se impulsó el mercado de activos asociado con el sector inmobiliario para ofrecerse a los inversionistas, que habían sido previamente transformados en activos líquidos a través de los SPV, gracias a la titularización, y adquiridos con apalancamiento.

El punto con estas apreciaciones es que las hipotecas, convertidas en títulos valores negociables en el mercado de capitales, se transforman en activos muy apetecidos por los inversionistas, con la esperanza de obtener réditos futuros. Si aumentan su precio como la demanda, se inicia así una espiral especulativa. En ese contexto, aumentan los precios de las viviendas y los títulos asociados a los que derivaron las hipotecas.

A comprar títulos hipotecarios concurren inversionistas de diversas partes del mundo, entre ellos europeos, atraídos por la fiebre del mercado inmobiliario. Cuando el precio del activo subyacente se incrementa porque la demanda se mueve en la misma dirección, se cumplen las expectativas de los inversionistas (endeudarse barato para adquirir títulos hipotecarios con apalancamiento), pero el declive posterior del precio de la vivienda en Estados Unidos y de los títulos valores a los que se habían convertido por la titularización, junto con la imposibilidad de pagar muchos créditos, origina una restricción de liquidez por la acumulación de préstamos contraídos para hacer inversiones apalancadas.

La lógica que impera en los inversionistas es endeudarse barato a corto plazo e invertir en activos de más largo plazo, buscando mayores márgenes de rentabilidad en títulos respaldados por hipotecas. La disponibilidad de recursos para invertir se incrementa gracias al efecto del apalancamiento, los bajos tipos de interés y la liquidez. Así también la financiación para el mercado inmobiliario, lo que contribuye a empujar sus precios al alza.

Aprovechando estas circunstancias, los inversionistas trasladan ingentes cantidades de dinero al sector inmobiliario, con el ánimo de obtener beneficios futuros extraordinarios y es justamente lo que atrae al sistema bancario a la sombra (Krugman, 2009:158). Cuando se revierte la dinámica de los precios, explota la burbuja inmobiliaria y se desploman los precios de los activos asociados con las viviendas como de las viviendas mismas y numerosas personas no pueden pagar los créditos hipotecarios (subprime); los inversionistas apalancados pierden su dinero y se produce una crisis bancaria, simbolizada por el cierre del Banco Lehman Brothers en Nueva York el 15 de septiembre del año 2008. El efecto de este estallido sería magnificado por el grado de apalancamiento de la economía. Con la titularización, el riesgo del crédito asociado a las hipotecas se transfirió a los mercados financieros, incluidos los inversionistas europeos. El primer país sacudido por la crisis fue Estados Unidos, por las inmensas deudas hipotecarias y porque instituciones financieras importantes se vieron enfrentadas a un deterioro gradual de la calidad de las inversiones. En resumen, lo que pasó en Europa y la crisis actual, fue un periodo de auge crediticio con primas de riesgo bajas, disponibilidad de liquidez, 
apalancamiento, crecimiento desmedido del precio de los activos y la generación de una burbuja especulativa en el sector inmobiliario, que terminó trasladándose al sector real.

La eurozona, es decir los estados que adoptaron el euro como moneda oficial, viven una triple crisis: de deuda, bancaria y de crecimiento, y tuvo diferentes elementos en su origen (Shanbaugh, 2012:157). El auge crediticio y endeudamiento excesivo, déficits en cuenta corriente, titularización, apalancamiento y laxitud fiscal, originaron el no pago de la deuda, crisis bancaria y contracción productiva. Para que algunos países ingresaran a la UE, tuvieron que acoger las regulaciones económicas impuestas por la Unión Monetaria. La deuda como proporción del PIB, no debía superar el $60 \%$ y el déficit fiscal el 3\%. Si países como Grecia, por ejemplo, acogía la regulación y estaba cobijado por la calificación crediticia de Alemania, tomar prestado llegó a ser no solo barato, sino relativamente sencillo y la adopción del euro propició condiciones más favorables para endeudarse. El resultado más previsible fue acceso al crédito barato por las dos circunstancias anotadas, lo que disparó el consumo y el endeudamiento de los hogares, especialmente en hipotecas y bienes no transables. En una muestra tomada en diez países desarrollados ${ }^{8}$, Minescu (2011:96) encontró que la deuda total aumentó del 200\% del PIB en el año 1995 hasta el 300\% en el año 2008. En los países periféricos de la eurozona (PICS), la proporción fue mayor.

Grecia, por ejemplo, en el año 2009 tuvo un déficit presupuestario estimado en 12\% del PIB, pero ya en el año 2008 su deuda había sido degradada por Fichts de AAA- hasta BBB +; los costos por intereses comienzan una espiral alcista y la situación empeora cuando S\&P y Moody's clasifican la deuda griega como basura. En marzo del año 2011 Grecia anunció un plan de austeridad plasmado en el aumento del impuesto al valor agregado, congelamiento de pensiones y de salarios públicos como condición para que en mayo del año 2010, la UE y el FMI desembolsaran 110.000 millones de euros, condicionado también esto a la privatización de empresas públicas por valor de 70.000 mil millones de dólares. En febrero del año 2012 el gobierno griego disminuyó el salario mínimo en 22\%, las pensiones en 15\% y suprimió 15.000 puestos de trabajo del sector público a cambio de nuevos préstamos de rescate; en ese mismo mes los países de la eurozona alcanzaron un acuerdo para darle a Grecia 130.000 mil millones de euros (Ver Minescu, 2011: 99). Con un gasto público disparado y una débil recolección de impuestos, excedió con creces las reglas fiscales de la UE. Sin la discrecionalidad para devaluar, perdió competitividad y el Estado intervino como empleador de última instancia. Una de las muchas consecuencias de la crisis griega fue el efecto contagio a otros países.

Al igual que Grecia, Portugal acumuló deuda pública junto con un déficit fiscal enorme, pero perdió competitividad por la dinámica de los salarios y la expansión de la UE hacia Europa

8. Reino Unido, España, Suiza, Francia, Italia, EE. UU., Alemania, Canadá, Japón, Corea. 
Oriental, pues desplazó la inversión extranjera directa a esos países a costa de Portugal. En mayo del año 2011, los ministros de finanzas de los países europeos aprobaron 78.000 millones de euros en calidad de préstamos para el rescate de Portugal.

En el caso español, el problema no se relaciona con el tamaño de la deuda, pues comparada con las de otros países miembros de la eurozona, era inferior a dos tercios del PIB. La situación tuvo que ver fue con la banca local y la crisis de las viviendas. Prestaron alrededor de 323.000 millones de euros a los promotores inmobiliarios, cifra cercana al 31\% del PIB; pero al final del año 2010 acumularon préstamos incobrables por 87.000 millones de euros. La exposición bancaria al sector de la construcción y el desempleo en aumento, le imprimen unas características particulares.

En contraste, las fuentes del crecimiento económico en la periferia europea se agruparon en torno a los servicios domésticos, la construcción, la expansión del sector público y estancamiento de las exportaciones. Los resultados fueron la acumulación de deuda pública y privada, así como la profundización del déficit en cuenta corriente en medio de abundantes flujos de capital. La política de endeudamiento hará que se desborde la deuda pública con un sesgo antiexportador por el estancamiento de los bienes transables, sacrificando la inversión productiva.

El mal llamado dinero fácil estimuló el aumento del gasto, incentivando la creación de una burbuja en la demanda interna, que por sus características, no favoreció la inversión productiva en Grecia, que con el estancamiento de las exportaciones, desató una crisis de productividad. Cuando sobreviene la crisis financiera global con las restricciones de liquidez relacionadas, Grecia no puede pagar la deuda contraída (crisis de deuda) y sobreviene la crisis bancaria, se agotan las fuentes de financiamiento barato y a cambio de un rescate financiero, tiene que llevar a cabo las medidas de austeridad. Cuando se amplifica el problema de la deuda soberana (es decir que se extiende por más de un país), hay un estancamiento de la productividad y crecimiento; como los países afectados pertenecen a la eurozona, no pueden devaluar ni emplear discrecionalmente la política monetaria.

Con la magnitud de la crisis aumenta el riesgo país y es muy difícil conceder préstamos a los PIGS, que ven aumentar el costo del endeudamiento en un mercado de capitales ilíquido. Con la acumulación de la deuda, la rentabilidad exigida alcanzaría un nivel donde a los gobiernos se les hace aún más difícil pagar. La pérdida de confianza entre los inversionistas conlleva a la degradación de la deuda por parte de las agencias calificadoras de riesgo, que aceleran y refuerzan la crisis de producción y desempleo, en medio de las más estrictas medidas de ajuste y austeridad.

\section{La Unión Europea, teoría de las relaciones internacionales y crisis}

Desde que en el año 1957 se fundó la Comunidad Económica del Carbón y del Acero -CECA-, Europa ha buscado la integración política y económica en un proceso, que de acuerdo con Haas (1968:16), actores políticos de varios contextos nacionales diferentes, son exhortados a 
cambiar sus lealtades, expectativas y actividades políticas hacia un nuevo centro, cuyas instituciones reclaman jurisdicción sobre los estados nacionales preexistentes, asociación que encierra un proceso social, por el desplazamiento de lealtades y un proceso político, con la construcción de nuevas instituciones con una injerencia directa en los asuntos de sus estados miembros (Díez, et. al. 2004:238-46). El resultado final es una nueva comunidad política, superpuesta a las ya existentes y personificada en los estados nacionales individuales.

Otro propósito de la integración era impedir un nuevo conflicto entre Alemania y Francia, consolidando una paz duradera sobre las bases de la integración política y socioeconómica. Desde el ámbito académico, la fase inicial de este hecho de la integración fue plantado por las primeras escuelas de pensamiento de las relaciones internacionales como el federalismo, el funcionalismo y el transaccionalismo. En su fase actual, lo explica el neofuncionalismo, el neorealismo/ intergubernamentalismo y el constructivismo. La evolución de la política europea se hace desde el gobierno multinivel y el neoinstitucionalismo.

A continuación, se hace una presentación sucinta de esas fases y teorías. El federalismo, plantea que los estados nacionales pierden derechos cuando no garantizan la seguridad política y económica a sus ciudadanos, entonces la evolución política y las formas de funcionamiento de la UE marchan hacia una federación de estados que en muchas situaciones sustituyen a estados nacionales (Spinello, 1972:68). La idea federal trasciende el ámbito del estado-nación hacia un estadio de mayor integración, que evolucionó desde la Comunidad Europea hasta la Unión Europea constitucional, políticamente federal adaptada a su situación, con lo que priorizan el aspecto institucional de la integración, el resultado de la unión voluntaria de estados y personas, con el propósito de reconocer, preservar y adaptar intereses, identidades y culturas disímiles en un acuerdo formal, bajo la idea de igualdad de asociación entre los miembros, la reciprocidad mutua para promover el bienestar entre los componentes del todo. Con la integración se reúnen voluntariamente actores políticos y naciones-estado, que dan forma colectivamente a una unidad supranacional con separación de poderes, donde las unidades políticas autónomas precedentes, declinan una parte de su soberanía para someterse a la voluntad común.

La teoría económica funcionalista clásica subraya los atributos tecnocráticos de la política económica y social en la integración comunitaria, junto con la creación de instituciones supranacionales que promuevan el bienestar económico (Dinan, (ed. 2000:245)). Estos elementos legitiman las instituciones, que en el largo plazo, evolucionan hacia una suerte de gobierno internacional. Por ende, la integración es el fruto de la aparición y crecimiento de las organizaciones internacionales resultantes del desarrollo de las fuerzas productivas en las sociedades industrializadas, porque dada la complejidad de los problemas socioeconómicos, solo pueden resolverse con la cooperación interestatal. Las organizaciones surgidas en estas circunstancias cooperan primeramente en las áreas técnicas, y aunque los estados nacionales ceden una parte de su poder, no son incorporados en una entidad política superior. 
La internacionalización de los problemas complejos está tutelada por las necesidades funcionales que generan ellas mismas, mecanismos de resolución colectiva de problemas I nivel internacional y formas organizacionales asociadas. Desde la esfera económica y social, aflora un marco propio para la resolución de estos problemas, y la cooperación internacional se legitima por el provecho mutuo derivado de una cooperación técnica que se traduce en resultados eficientes.

El transaccionalismo es una teoría de cambio en la política internacional llamada también pluralismo o enfoque de las comunicaciones, que explora el desarrollo de vínculos entre sociedades como base para la integración(Deutsch, 1968:195). La guerra como medio de resolver las diferencias entre estados se vuelve obsoleta. Se trata de comunidades seguras entre las que se erradica la posibilidad de una conflagración y la situación lograda con este proceso se denomina transaccionalismo. Las comunidades seguras son entidades en las que los gobiernos que las componen optan por retener sus identidades legales independientes o conformar una fusión institucional más amplia (Tönnies, 2011:160). Como el sentido de comunidad entre estados es una función del nivel de comunicación entre ellos (Rosamond. 2000:14-16). Las comunicaciones y las transacciones permiten alcanzar la confianza y la lealtad, necesarias para integrarse y crear las condiciones para poder alcanzar la paz (Deutsch, 1957:5). La integración actual, como ya se indicó, se expone desde el neofuncionalismo, el neorrealismo y el constructivismo. El neofuncionalismo supone la síntesis entre el funcionalismo teórico (Mitrany: 1966:35) y una visión pragmática del mundo de la administración (Monnet: 1978:9). En la explicación del proceso de integración introducen una dimensión política (Mansour, 2011:1). Los actores políticos nacionales desplazan sus lealtades a un centro político nuevo establecido en instituciones que tienen jurisdicción sobre los estados que preceden al orden. Se conforma una entidad supranacional a partir de las acciones graduales estimuladas por los intereses concertados de los actores políticos, que transfieren gradualmente parte de su propio poder con el fin de facilitar las condiciones políticas y económicas del ámbito supranacional. En el proceso de integración, los actores resuelven las discrepancias con arreglos contractuales en aspectos técnico-funcionales en algunas áreas sectoriales. Con la gestión cooperativa y la resolución de problemas conjuntos, la cooperación se generaliza a otras áreas funcionales relacionadas, que finalmente se desbordan hacia temáticas eminentemente políticas, donde se inicia un proceso gradual de integración bajo la lógica de integración por sectores; la comunitarización supranacional de las funciones estatales en una sucesión de áreas políticas de vecindad, que estimula una integración cuasiautomática a través de los efectos de desbordamiento. Los actores políticos juegan un papel concluyente en el proceso de armonizar la resolución de problemas con las disposiciones institucionales apropiadas, y transfieren sus lealtades y expectativas constantemente al ámbito supranacional, lo que legitima y estimula el proceso de integración.

Para el constructivismo, los componentes básicos de la realidad internacional son materiales e ideacionales. Los factores ideacionales tienen dimensiones normativas e instrumentales que expresan intencionalidades individuales y colectivas que no son independientes de tiempo y 
lugar (Ruggie, 1998:33). Díez (1999), identifica dos tipos de enfoques constructivistas: uno social que pregunta por el carácter de la realidad social en la tradición de Giddens y Katzenstein y el constructivismo teórico que investiga acerca de la condición y el estado del conocimiento humano de la realidad. Las preguntas de investigación típicas del constructivismo europeo versan sobre las consecuencias de la interacción social de los estados en el sistema internacional, las consecuencias de las normas nacionales sobre la política internacional, el impacto de las normas europeas sobre los cambios en las políticas nacionales, y la relevancia de la imagen del gobierno sobre los actores políticos europeos.

La evolución del sistema de gobierno europeo (polity) se ha explicado desde los enfoques de gobierno multinivel, el neoinstitucionalismo y el consociacionalismo. El primero representa la fase avanzada de la política europea, pues es un acuerdo para la toma de decisiones que se acopla a una multiplicidad de actores políticos independientes, públicos y privados, en distintos niveles de agregación territorial, que no asigna la competencia política exclusiva a ninguno de esos niveles. Dado que la acción política sucede en varios niveles de gobierno, la autoridad, en lugar de concentrarse, se dispersa. La idea implica que el número de actores significativos dentro del sistema de gobierno se multiplica y por lo tanto supone competencias entre distintos niveles de gobierno, en los que interactúan los actores políticos en niveles superpuestos. Los políticos de los estados miembros serían apenas un conjunto de actores políticos que conforman un conjunto de redes para realizar políticas globales en diferentes niveles (multinivel).

La nueva institucionalidad y los enfoques institucionalistas, se construyen en torno a la aserción de que las instituciones sí importan, sobre todo por la forma en que éstas afectan los resultados políticos. Hay tres tipos de nuevo institucionalismo; el histórico, que estudia la distribución del poder en los acuerdos institucionales y las formas en que estos resultan en dependencia del camino, es decir, que el resultado del proceso depende de su entera trayectoria. Cabe decir que la secuencia de decisiones tomadas por los actores políticos en un estado presente, es el resultado de decisiones tomadas a lo largo de la trayectoria (historia o path dependence) del proceso, donde se destacan las consecuencias indeseables en el proceso, así como la relación entre las instituciones y factores que le dan forma a las actividades políticas. En segundo lugar, la elección racional supone una explicación sobre la conformación de las instituciones; presume que son estables (están en equilibrio), pero también establece los procedimientos y las restricciones que determinan las reglas del juego social, restringe las acciones de los actores políticos, y establece las sanciones por violar las reglas establecidas. Desde el enfoque sociológico, se analiza el cómo las formas y las prácticas institucionales se pueden explicar desde la cultura. Ese nuevo institucionalismo es un enfoque muy diverso compuesto fundamentalmente por diferentes escuelas de pensamiento. Por último, la segmentación social, como un modelo que proporciona ideas sobre las características centrales de las entidades, como los estados, que están divididos profundamente en su interior, son capaces de funcionar de una manera relativamente estable. 
Aun lo anterior, la crisis genera malestar por las consecuencias derivadas del ajuste fiscal, porque la contracción de la producción y la expansión del desempleo tocan directamente el bolsillo de los ciudadanos, quienes responden con movilizaciones masivas a pesar del proceso de integración. Las consecuencias de la crisis sobre las relaciones entre países al interior de la Unión Europea, se dan por lo menos en dos niveles. El primero es la relación existente entre los países de la UE, pues los que están en crisis, se ven como estados poco consecuentes con las políticas comunitarias y los destinatarios de recursos de otros países que han impulsado inversiones que magnifican la productividad del trabajo. Es decir, un sentimiento de rechazo para Grecia; pero en el caso de España la crisis amenaza la integridad del estado español mismo. Impera también el sentimiento de que Alemania impone la disciplina fiscal a los países en crisis, pero es indiferente ante el deterioro de la situación social en el continente. Y esto también genera tensiones.

Otro dilema se asocia con la posibilidad de profundizar la unión con el reto de coordinar economías que son divergentes. Unas en plena crisis, otras menos afectadas, y otras que están liderando el escaso crecimiento europeo. A nivel de los gobiernos, se teme que la falla del euro como una moneda continental, puede frenar una mayor integración económica y originar severas divisiones políticas; además de que existe una brecha entre el centro y la periferia, entre países como Alemania y Francia, que ejercen presión sobre los PIGS. De hecho se presenta desacoplamiento entre la periferia y el núcleo, lo que quiere decir que no todos los países han sido afectados igualmente. En el primer caso, hay una recuperación especialmente para Alemania, mientras la periferia aún se debate entre la crisis. Por ejemplo, mientras Alemania y Francia componen el 50\% del PIB de la eurozona, los países mencionados apenas el 18\%, de acuerdo a informe del Deutsche Bank.

Si bien las tensiones no son nada nuevo dentro de la UE, estas se han presentado entre los países que promueven una integración más profunda y entre aquellos que son partidarios de una posición intergubernamental más fuerte para resguardar mejor sus intereses nacionales y su soberanía; de manera que algunos países se han alejado de ciertos aspectos acordados para la integración, tales como los pasaportes y las visas para viajar por toda Europa (Reino Unido y Dinamarca), el euro como moneda única (Reino Unido, Dinamarca y Suecia), justicia y asuntos domésticos (Reino Unido, Irlanda y Dinamarca). Otro punto desfavorable está dado por la división entre los estados catalogados como randes y los pequeños. Estos últimos son cuidadosos frente al hecho de que las iniciativas que se tomen al interior de la UE, les permitan a los países grandes dominar el proceso de toma de decisiones. La ampliación de la UE hacia el oriente, ha incluido países que pertenecieron a la llamada Cortina de Hierro (dominio soviético), lo que crean también tensión con las mismas reformas europeas con Rusia y el Oriente Medio, y fricciones con los miembros más viejos de la Unión ante el evento de una extensión de la Unión hacia áreas de influencia rusa. También las migraciones son consideradas amenaza a la seguridad europea. 


\section{CONCLUSIONES}

Una de las conclusiones tiene que ver con la magnitud y duración de la crisis. Las tasas de crecimiento han sido muy elevadas en la llamada periferia europea así como el desempleo, lo que junto a las severas medidas de austeridad, se traduce en retroceso de la calidad de vida para los ciudadanos de los países emblemáticos de la crisis, aunque reina la incertidumbre sobre el momento en que pueda superarse. En segundo lugar, las crisis financieras han sido un fenómeno recurrente en el siglo XXI, pero los períodos entre crisis son cada vez menores. La integración europea es un proceso que lleva por lo menos 60 años y se inició con la esperanza de evitar un conflicto entre Francia y Alemania, y que se desbordó a la economía. La posibilidad de afianzar la Unión Europea se topa con el reto de coordinar economías que son divergentes, donde además, se teme que la falla del euro como una moneda continental puede frenar una mayor integración económica y originar severas divisiones políticas; también porque se presenta división europea entre el centro y la periferia. De hecho, se presenta desacoplamiento entre la periferia y el núcleo, y la periferia aún se debate entre la crisis, existiendo todavía incertidumbre sobre el momento en que se pueda superar.

\section{BIBLIOGRAFÍA}

- $\quad$ Arnaudo J.; Querol L.; Pérez G. (2003). Crisis del Tequila: Sus efectos sobre el sistema financiero argentino y sus normas prudenciales.

- Bonesmo-Fredriksen, K. (2012). Income Inequality in the Europena Union. (Working Paper No. 952). OECD Publishing.

- Carlson, M. (2006). A Brief History of the 1987 Stock Market Crash. Washington: Federal Reserve Board.

- Chiodo A. J.; Owyang M. T. (2002). A Case Study of a Currency Crisis: The Russian Default of 1998: The Federal Reserve Bank of St. Louis.

- Deutsch, K. et al. (1957). Political Community and the North Atlantic Area. Princeton University Press, New Jersey.

- Deutsch, K. et al. (1967). France, Germany and the Western Alliance: A Study of Elite Attitudes on European Integration and World Politics. Charles Scribner's Sons, New York.

- $\quad$ Diez T.; Wiener, A., 2004: European Integration Theory. Oxford: Oxford University Press.

- Dinan D. (ed.), (2000): Encyclopedia of the European Union. Boulder, London: Lynne Rienner. 
- $\quad$ Eurostat. (2013). Statistics Database. http://epp.eurostat.ec.europa.eu/portal/page/portal/ eurostat/home/

- $\quad$ GARP. (2004). The History of Financial Risk Management: A (Mostly) Personal View. Global Association of Risk Professionals. New Jersey.

- $\quad$ Griffith-Jones S.; Sunkel O. (1987). Debt and Development Crisis in Latin America: The End of an Ilussion. London: Oxford University Press.

- $\quad$ Haas, E. B. (1968). The Uniting of Europe. 1950-1957. Stanford Stanford University Press.

- $\quad$ Hodrick R; Prescott E. (1980). Postwar U.S. Business Cycles: An Empirical Investigation. Journal of Money, Credit and Banking, 29(1), 1-16.

- Kapoor, S. (Ed.). (2010). The financial crisis:causes \& cures. Brussels: FES Brüssel, Bertelsmannstiftung, ETUI.

- $\quad$ Kidland F.E; Prescott E. C. (1982). Time to Build and Aggrregate Fluctuations. Econometrica, 50(6), 1345-1370.

- $\quad$ Kindleberger, C. (1978). Manias, Panics, and Crashes. New Yor: Basic Books.

- Krugman, P.(2009). The Return of Depression Economics and the Crisis of 2008: Norton, New York.

- $\quad$ Lane P. (2012). The European Sovereign Debt Crisis. Journal of Economic Perspectives, 26(3), 49-68.

- $\quad$ Laven Z.; Santi F. (2012). EU Austerity and Reform: A Country-by-Country Table. Retrieved from http://www.europeaninstitute.org/April-2012/eu-austerity-and-reform-a-contry-bycountry-table-updated-may-3.html.

- $\quad$ Levine, L. (2009). The labor Market During Great Depression and the Current recession. Whashington: CRS Report to Congress.

- $\quad$ Liu Y.; Morley, B. (2012). "Sovereign credit default swaps and the macroeconomy," Applied Economics Letters, Taylor and Francis Journals, vol. 19(2), pages 129-132, february.

- $\quad$ Long Jr. J. B; Plosser C. I. (1883). Real Business Cycles. Journal of Political Economy 33(3), 39-69.

- $\quad$ Lucas R. E. (1981). Studies in Business Cycle Theory Cambridge. Cambridge: The MIT Press.

- Mankiw, G. (1989). Real Business Cycle: A New Keynesian Perspective. Journal of Economic Perspectivs, 3(3), 79-90. 
- Minescu, A. (2011). The Debt Crisis, Causes and Implications. Petroleum-Gas University of Ploiesti Bulletin, LXIII (2), 95-104.

- Monnet, J. (1978). Memoirs. New York, Doubleday and Co.

- $\quad$ Nakagawa R.; Uchida, H. (2007). Herding Behavior in Bank Lending: Evidence from U.S. Commercial Banks Journal of Financial Internediation, 16(4), 555-583.

- Noy, I. (2002). Banking Crises in East Asia: The Price Tag of Liberalization? Analysis from the East-West Center No. 78. Washington, The East-West Center.

- $\quad$ Radelet, S.; Sachs, J. (1998). The Onset of the East Asian Financial Crisis. Cambridge, NBER.

- $\quad$ Reza S.; Lim V.; Pontines V. (2011). Post Global Financial Crisis: Issues and Challenges For Central Banks of Emerging Markets. Staff Paper No. 80. Kuala Lumpur, SEACEN.

- $\quad$ Romer, C. (2003). Great Depression. Enciclopaedia Britannica. Chicago: Encyclopedia Britannica, INC.

- Rosamond, B. (2000): Theories of European Integration. Houndsmills: MacMillan.

- $\quad$ Rothbard, M. (2000). America's Great Depression. Fifth Edition. Auburn, The Ludwig von Mises Institute.

- Ruggie, J. (1998): Constructing the World Polity: Essays on International Institutionalization. New York: Routledge.

- Saxton, J. (2003). Argentina's Economic Crisis: Causes and Cures. Whashington: United States Congress.

- $\quad$ Shambaugh J.; Anand M.; Gupta G.; Dash R. The Euro's Three Crises. Washington: McDonough School of Business, Georgetown University and NBER.

- Spinelli, A. (1972): The Growth of the European Movement since the Second World War, in: Mark Hodges (ed.): European Integration. Harmondsworth: Penguin.

- $\quad$ Stiglitz, J. (Arestis P.; Basu S.). Los Felices 90: La Semilla de la Destrucción. Bogotá: Taurus.

- $\quad$ Thomassen J. A. (Ed.). (1990). Economic Crisis, Dissatisfaction and Protest. Berlín: De Gruyter.

- Tondo, C. (2009). Effects of the dot-com crash on pensions in industrialized countries.

- US Departament of Treasury. (2012). The Financial Crisis Response in Charts. Washington: US Departament of Treasury. 